\title{
Спектрально-селективное подавление фундаментальной моды сердцевины в световоде с поглощающими стержнями
}

\author{
$\underline{\text { T.А. Кочергина* }}^{*}$ С.С. Алешкина, М. М. Бубнов, М.Е. Лихачев
}

Институт общей физики им. А.М. Прохорова РАН, Научный центр волоконной оптики им. Е.М. Дианова

*E-mail: tatyana@fo.gpi.ru

DOI: 10.31868/RFL2020.158-159

Ранее [1] нами был предложен и экспериментально апробирован новый подход для подавления нежелательных мод сердцевины световода путем внесения в его оболочку соответствующим образом подобранных поглощающих стержней с показателем преломления выше уровня кварцевого стекла. Модификация оболочки световода изменяет волноводную дисперсию и характер зависимости эффективного показателя преломления ряда групп мод структуры от длины волны, приводя к тому, что на выделенных (резонансных) длинах волн пара мод может иметь близкие значения эффективного показателя преломления, подобное распределение интенсивности поля и быть одновременно локализованными и в области сердцевины, и в области поглощающих стержней. Таким образом, на резонансных длинах волн предложенная методика способствует деформации формы подавляемых мод сердцевины и увеличению их потерь на распространение за счет поглощения в стержнях. В качестве активной добавки поглощающих стержней, в таком случае, могут быть использованы редкоземельные элементы [2], имеющие полосы поглощения на соответствующих длинах волн.

В настоящей работе мы показываем возможность расширения области применения предложенной методики, а именно демонстрируем возможность реализации спектрально-селективного подавления распространения фундаментальной моды одномодового световода. Методика, развитая в настоящей работе, актуальна для создания волоконных лазеров и усилителей, излучающих на длинах волн, где генерация затруднена вследствие наличия у активной среды энергетически более выгодных излучательных переходов. Кроме того, предложенный в работе подход также может применяться для подавления вынужденного рамановского рассеяния. Уникальной особенностью рассмотренного механизма подавления фундаментальной моды сердцевины является контролируемая (путем изгиба) спектральная ширина области, где вносятся избыточные потери. Применимость методики рассмотрена на примере $\mathrm{Yb}$-волоконного лазера, излучающего на длине волны 977 нм.

При моделировании для простоты интерпретации сначала нами была рассмотрена конструкция световода только с одним поглощающим стержнем (вставка рисунка 1a). Сердцевина имела следующие параметры: Dcore=10 мкм, $\Delta \mathrm{n}=0.002, \lambda_{\text {cutoff }}=970$ нм. Параметры стержня были подобраны так, чтобы положение резонанса было на длине волны 1030 нм в прямом световоде. Оценка параметров резонансного взаимодействия была осуществлена посредством вычисления содержания доли мощности подавляемой моды сердцевины в области стержня.

Согласно нашим расчетам, на ширину пика резонансного взаимодействия влияет расстояние (S) от оси световода до оси стержня (ширина пика растет при 
уменьшении расстояния), а так же величина показателя преломления поглощающего стержня (ширина пика растет при уменьшении показателя преломления стержня). При этом на интенсивность пика оказывает влияние только показатель преломления поглощающего стержня.

Исследования, проведенные для конструкции изогнутого световода, показали, что направление изгиба (относительно пространственного положения стержня, вставка рисунка 1а) и радиус изгиба влияют на ширину и интенсивность пика резонансного взаимодействия. Кроме того, изгиб световода оказывает существенное влияние на смещение положения длины волны резонанса (рисунок 1a). Как следствие, при усреднении всех возможных направлений изгиба область резонансного взаимодействия изогнутого световода оказывается шире пика резонансного взаимодействия прямого световода. При этом ширина резонанса зависит от радиуса изгиба. Выбор конструкции световода, как минимум с тремя поглощающими стержнями, расположенными в вершинах равностороннего треугольника (вставка рисунка 1б), приводит к тому, что практически при любом направлении изгиба для разных стержней реализуются разнонаправленное смещение пика. В то же время при рассмотрении реальной конструкции световода, скрученного в бухту фиксированного диаметра, направление изгиба изменяется по длине световода, и усредненный спектр доли мощности моды сердцевины в поглощающем стержне имеет профиль близкий к прямоугольному (рисунок 1б).

Интересно отметить, что путем изменения расстояния между каждым стержнем и осью световода, возможно регулировать чувствительность уширения области резонанса к изгибу, и тем самым контролировать ширину спектральной области, где распространение фундаментальной моды должно быть подавлено.
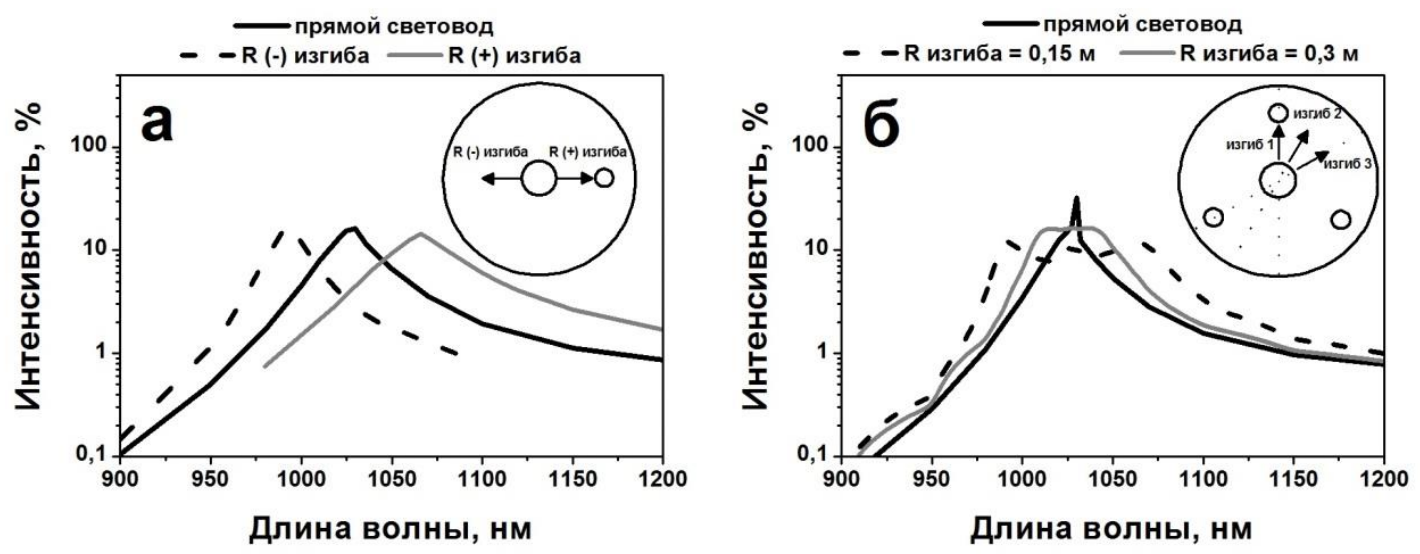

Рис. 1. Рассчитанный спектр поглощения прямого и изогнутого (в неравнозначных направлениях) световода с одним (а) стержнем ( $\mathrm{d}_{\text {стержня }}=2.28$ мкм, $\Delta \mathrm{n}=0.01, \mathrm{R}_{\text {изгиба }}=0.15$ м) и с тремя (б) стержнями ( $\mathrm{d}_{\text {стержня }}=2.28$ мкм, $\Delta \mathrm{n}=0.01, \mathrm{R}_{\text {изгиба }}=0.3 \mathrm{M}$ и 0.15 м). На вставках -схематичное изображение рассмотренных конструкций световодов.

Работа выполнена при поддержке Российского научного фонда (грант № 16-12-10553).

\section{Литература}

[1] S.S. Aleshkina, T.A. Kochergina et al. Scientific Reports 10, 7174 (2020)

[2] Т.А. Кочергина, С.С. Алешкина и др. Квантовая электроника 48, 733 (2018) 